\title{
A welcome to Dr Anthonisen and an end-of-term report card
}

\author{
Norman L Jones MD, Editor-in-Chief, Canadian Respiratory Journal
}

$\mathrm{I}$ $\mathrm{t}$ gives me great pleasure to announce that my successor as Editor-in-Chief of the Canadian Respiratory Journal is Dr Nick Anthonisen. He is one among only a small handful of Canadian respirologists who truly need no introduction, but some indication of his wide experience and accomplishments is deserved.

Dr Anthonisen grew up in the New England area of the United States and graduated from Harvard Medical School in 1958. After clinical training in North Carolina, his career track was set by a three-year research fellowship in pulmonary physiology with Dr SM Tenney at Dartmouth Medical School. He completed his clinical training at the Royal Victoria Hospital in Montreal, Quebec, and in 1964, he joined its stellar group in the pulmonary division. He worked with Dr David Bates on the development of radioactive xenon studies of regional lung function, and also published studies on lung mechanics and the control of breathing. He continued to follow these research interests when he moved to the University of Manitoba in Winnipeg, Manitoba to head the Section of Respiratory Diseases in 1975, and he also became involved in large scale clinical trials on chronic obstructive pulmonary disease. These landmark studies included the Nocturnal Oxygen Therapy and Intermittent Positive Pressure Breathing trials, a trial of antibiotics in acute exacerbations of chronic obstructive pulmonary disease (COPD), and the Lung Health Study, all of which cemented his reputation as an outstanding clinical researcher. From 1988 to 1999, he served as the Dean of Medicine at the University of Manitoba, and afterwards, he returned to research and clinical practice. It would be hard to imagine a more impressive background for the Editor-in-Chief of the Journal, and I extend my appreciation and thanks to him for accepting this position.

As part of the process of leaving this position, I thought that a look back at how the Journal has performed on 'housekeeping issues' would be worthwhile. I have been surprised at how often I am contacted, usually by organizations who apparently write up research papers for pharma- ceutical companies, to inquire about length of manuscript review time and how long it takes to publish a paper in the Journal. Interestingly, I do not believe that any of these calls were followed by a submission, but that is by the by. So, for anyone who would like to know but was too afraid to ask, here are data for the past two years.

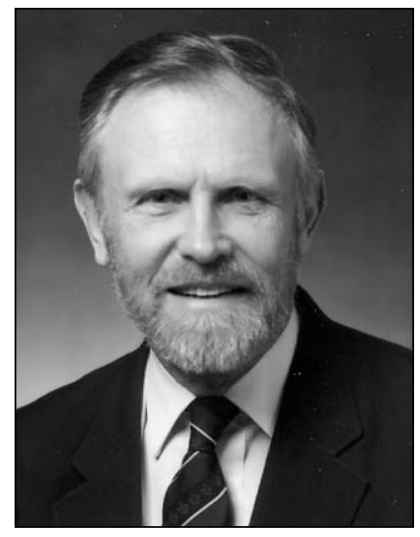

The analysis is based on 161 submissions and obviously excludes papers that are currently being assessed. The mean time ( \pm SD) for reviews to be returned to authors was $4.4 \pm 2.52$ weeks, with a median response time of 3.6 weeks. There was then a delay in authors returning revised manuscripts of $7.9 \pm 6.67$ weeks; however, this excludes papers not returned. Sixteen papers were not resubmitted, despite at least reasonably favourable reviews and at least one reminder. I have to wonder why, bearing in mind the adage that a piece of scientific work is not complete until publication. The average time between submission and acceptance was $16 \pm 9.3$ weeks, and between submission and publication was $30 \pm 11.9$ weeks. The rejection rate was $18 \%$. Case reports constituted $26 \%$ of submissions.

Of course, statistics are meaningless without some assurance of quality, and it is possible that our rejection rate of $18 \%$ may strike readers as too small. In response, I can say that rejected authors would not agree, and that acceptance invariably depends on the reviewers' reports. Occasionally, there is disagreement between two reviewers; my habit is to act as arbitrator and make a decision on acceptance. This habit was born long ago when the Journal of Applied Physiology made us wait for 18 months for a review of a paper my colleagues and I had submitted; when it was finally returned, there were six reviews, three in favour and three 
against. We tried to argue that a paper that is controversial deserves publication, but it was a memorable and long struggle that I would not wish on any author contributing to the Journal. Throughout my tenure, I have considered myself extremely fortunate to have been helped by a large cadre of expert reviewers; the figures above show them to be prompt, and their reviews have been almost invariably helpful and constructive. My heartfelt 'thank you' goes out to them all.

I would encourage readers with criticisms related to the quality of papers we have published or any other topic to speak up now, especially because I will no longer be in any position to exact retribution! Feedback would also be appreciated regarding some of the features that we have incorporated into the Journal over the past few years. These include the Modern Classics Revisited series, Vignettes, Information for Patients and the abstracts for the Annual Meeting and Residents' Competition.
To the Journal's Editors at Pulsus (who were, in turn, Janet O'Flaherty, Anne Federer, Seanna-Lin Brodie-Keys, Nicola Cason and Jill Toffoli), I extend my heartfelt gratitude for their untiring efficiency, for bearing with my scant ability to meet deadlines and for exerting their editorial skills to such good effect that I believe the Journal's English has not been bettered; also, I can recall only one erratum that needed publication during our eight-year history. Robert Kalina, Pulsus Group's Publisher, and Ann LeBlanc, the Vice-President, have been unfailingly supportive and imaginative both in the production of the Journal and in its relationship with the Canadian Thoracic Society.

So, you can see that I am in debt to many at the end of an exceptionally enjoyable time as Editor-in-Chief. I look forward to applauding the Journal's future progress from the sidelines. 


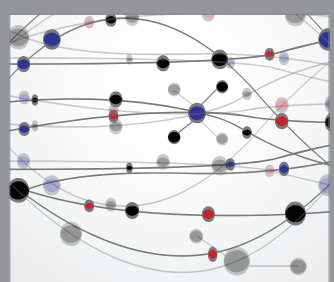

The Scientific World Journal
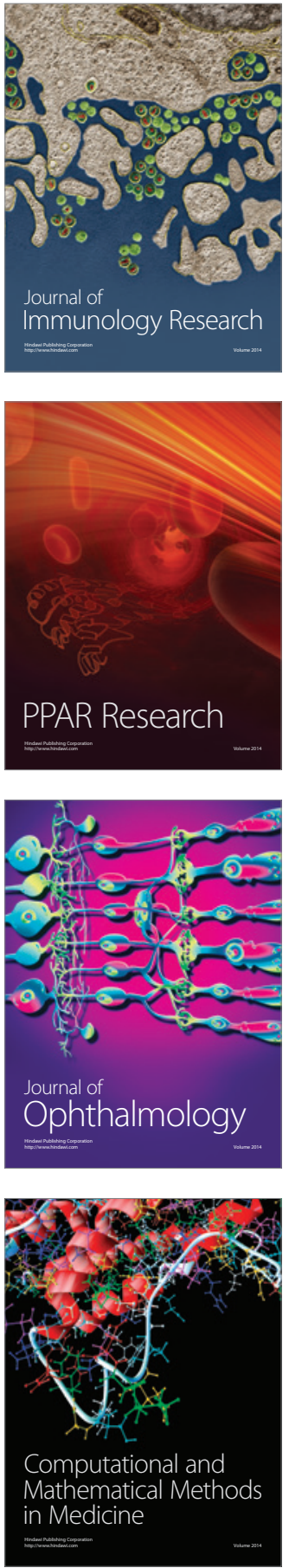

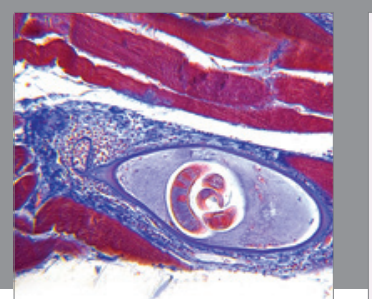

Gastroenterology Research and Practice

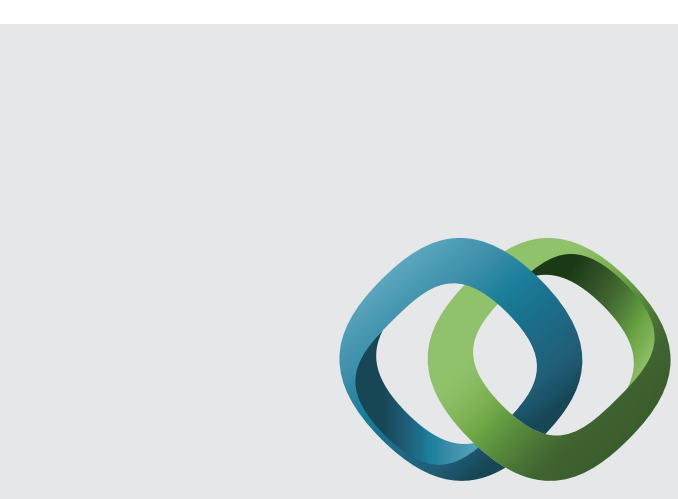

\section{Hindawi}

Submit your manuscripts at

http://www.hindawi.com
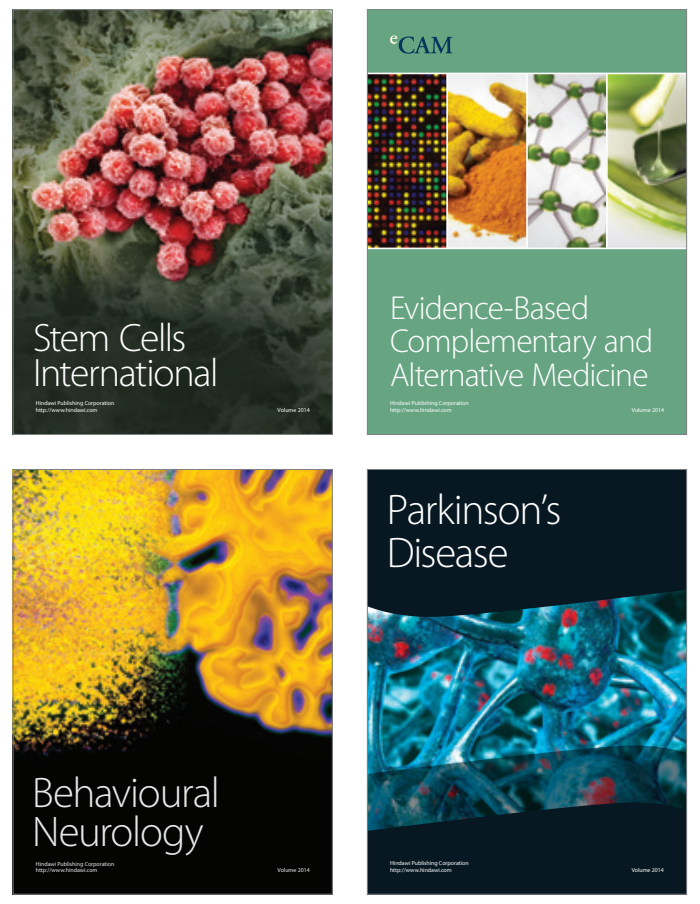
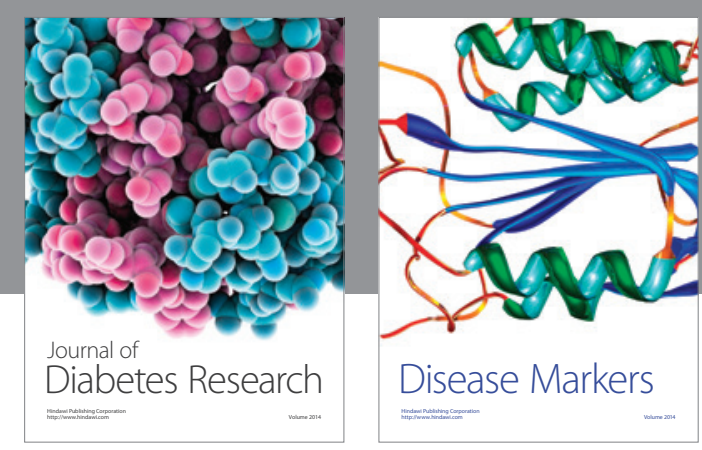

Disease Markers
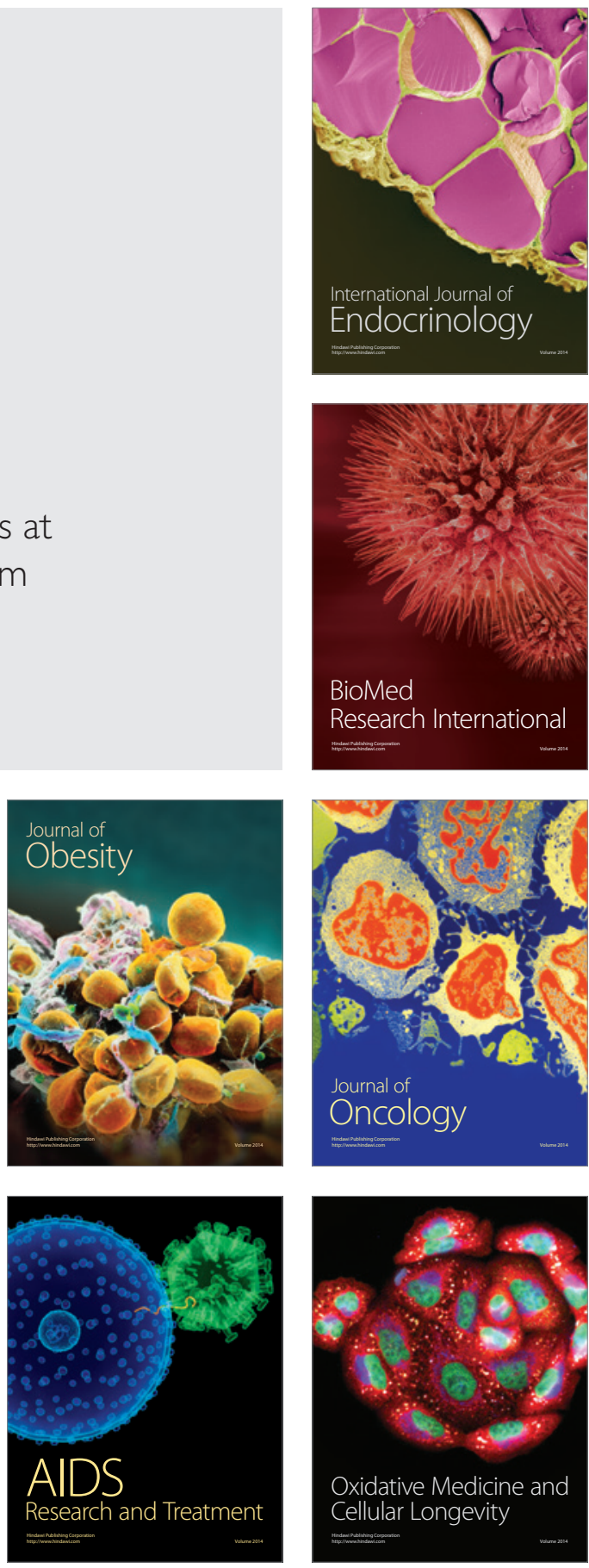